\title{
Constitutive mutants of the protein kinase STE11 activate the yeast pheromone response pathway in the absence of the $G$ protein
}

\author{
Brian J. Stevenson, ${ }^{1}$ Nelson Rhodes, ${ }^{2}$ Beverly Errede, ${ }^{2}$ and George F. Sprague Jr. ${ }^{1,3}$ \\ ${ }^{1}$ Institute of Molecular Biology and Department of Biology, University of Oregon, Eugene, Oregon 97403 USA; ${ }^{2}$ Department \\ of Chemistry, University of North Carolina, Chapel Hill, North Carolina 27599 USA
}

\begin{abstract}
STE4 encodes the $\beta$-subunit of a heterotrimeric guanine nucleotide-binding protein ( $G$ protein) that is an early and essential component of the pheromone signal transduction pathway. From a ste4 deletion strain we have isolated both dominant and recessive suppressors that show increased transcription of pheromone responsive genes and have regained the ability to mate, albeit at a low level. Each of these suppressor mutations suppresses ste 4 and ste 5 deletions but not deletions in STE7, STE11, or STE12. Among the dominant mutations, we have identified two alleles of STE11, a gene that encodes a protein kinase activity essential for mating. One allele contains an alteration in the putative regulatory domain of the protein kinase; the second allele has an alteration in the catalytic site. In strains carrying these mutations, a second protein kinase required for mating, STE7, becomes hyperphosphorylated, just as it does in wild-type cells treated with pheromone. Thus, a protein kinase cascade appears to be an essential feature of the response pathway and probably connects the receptor/G protein to an identified transcription factor, STE12.
\end{abstract}

[Key Words: STE11 protein kinase; yeast pheromone response; signal transduction]

Received February 18, 1992; revised version accepted April 6, 1992.

The response to extracellular signals is an essential element in the control of the growth and differentiation of all living cells. In haploid cells of the yeast Saccharomyces cerevisiae, the differentiation pathway from vegetative growth to the sexual cycle is controlled by the mutual exchange of extracellular, diffusible peptide pheromones: Cells of mating type $\alpha$ produce $\alpha$-factor and respond to a-factor, and cells of mating type a produce a-factor and respond to $\alpha$-factor. Exposure of cells to the opposite mating pheromone generates an intracellular signal that leads to a variety of physiological changes that prepare the cell for mating. This suite of changes includes transcription induction of genes required for cell and nuclear fusion, arrest of the mitotic cell cycle in the $G_{1}$ phase, and emergence of a projection from the cell body (shmoo formation). These last two changes also result, at least in part, from altered transcription of appropriate genes. Thus, to a first approximation, the pheromone response pathway is a pathway in which the pattern of transcription is altered (for review, see Cross et al. 1988; Marsh et al. 1991).

Components or regulators of the signal transduction pathway have been identified by mutations that abolish

${ }^{3}$ Corresponding author. pheromone response or, in a few cases, by mutations that lead to constitutive signaling even in the absence of pheromone. Genetic and physiological experiments with these mutant strains have led to the following picture of the response pathway. Detection of pheromone is mediated by specific cell-surface receptors, encoded by STE3 in $\alpha$ cells and by STE2 in a cells, that belong to the seven-transmembrane receptor family (Jenness et al. 1983; Burkholder and Hartwell 1985; Nakayama et al. 1985; Hagen et al. 1986). These receptors couple to a heterotrimeric G protein (Dietzel and Kurjan 1987; Miyajima et al. 1987; Nakafuku et al. 1987; Jahng et al. 1988; Whiteway et al. 1989; Blumer and Thorner 1990) and thereby activate an intracellular pathway that is common to a and $\alpha$ cells (Bender and Sprague 1986; Nakayama et al. 1987). Binding of pheromone to receptor is believed to lead to the exchange of GTP for GDP on the $G_{\alpha}$ subunit and to the attendant release of $G_{\beta \gamma}$. In contrast to most mammalian cells and to fission yeast (Obara et al. 1991), in S. cerevisiae, free $G_{\beta \gamma}$ propagates the signal to downstream targets. This conclusion follows from the observation that deletion of $G_{\alpha}$ [encoded by GPA1 (SCG1)] or overexpression of $\mathrm{G}_{\beta}$ (encoded by STE4) activates the pathway in the absence of pheromone (Dietzel and Kurjan 1987; Miyajima et al. 1987; Jahng et al. 1988; Cole et al. 1990; Nomoto et al. 1990; 
Whiteway et al. 1990). Although the immediate target of $\mathrm{G}_{\beta \gamma}$ is not known, a terminal target is STE12, a DNAbinding protein that binds to the promoter regions of inducible genes (Dolan et al. 1989; Errede and Ammerer 1989). These genes include FUS1 and KAR3, required for cell and nuclear fusion (McCaffrey et al. 1987; Trueheart et al. 1987; Meluh and Rose 1990), and FUS3 and FAR1, required for $G_{1}$ arrest (Chang and Herskowitz 1990; Elion et al. 1990). STE12, therefore, plays a pivotal role in the execution of the pheromone-induced changes in cellular physiology.

Although there is a fairly concrete view of the events that occur at the cell surface and in the nucleus, how the signal is transmitted between these two sites is not known. Five genes that may be involved in transmitting the signal have been identified by the isolation of nonresponsive mutants. Four of these genes-STE7, STE11, FUS3, and KSS1-are predicted to encode protein kinases (Teague et al. 1986; Courchesne et al. 1989; Elion et al. 1990; Rhodes et al. 1990). In vitro kinase activity has been demonstrated for the STE11 protein (Rhodes et al. 1990). The role of the fifth gene, STE5, is elusive. Because loss-of-function mutations in these genes block the phenotype associated with the absence of $G_{\alpha}$ or overexpression of $G_{\beta}$, it has been inferred that these genes control steps subsequent to the $G$ protein. Other interpretations are possible, however. For example, the STE gene products might be required to make the $G$ protein competent to transmit a signal. The relationship between gene products thought to participate in the same process is rigorously established only by examining the phenotype of reciprocal double mutants involving gainof-function and loss-of-function alleles for both genes. Nevertheless, in keeping with the possibility that at least one protein kinase functions at a post-G protein step in signal transmission, STE12 has been shown to be phosphorylated rapidly after pheromone treatment, and the degree of its phosphorylation correlates with its transcriptional activity (Song et al. 1991).

To gain insight into how the pheromone-generated signal is propagated from $G_{\beta \gamma}$ to STE12, we have isolated suppressors that restore signal propagation in a strain lacking $G_{\beta}$ as a result of a deletion of the structural gene (STE4). We reasoned that mutations that activate the pathway downstream of the G protein would include dominant mutations in known STE genes or would identify new components in the signaling cascade. Here, we report the isolation of dominant STE11 alleles that appear to encode hyperactive or unregulated forms of the protein kinase. Strains harboring these mutations exhibit a high level of expression of pheromone-inducible genes, exhibit morphological alterations characteristic of pheromone response, and have regained some capacity to mate. Strikingly, these mutants also exhibit hyperphosphorylation of the STE7 protein kinase, a biochemical alteration seen in wild-type cells after pheromone treatment (Z.-Q. Zhou and B. Errede, unpubl.). Thus, these genetic and biochemical data suggest that STE11 phosphorylates a protein kinase and that a kinase cascade is an integral part of the pheromone response pathway.

\section{Results}

Isolation of ste $4 \Delta$ suppressors that restore mating

The FUS1 gene is transcriptionally regulated by pheromone and by the products of the STE4, STE5, STE7, $S T E 11$, and $S T E 12$ genes. In a wild-type $S T E^{+}$strain, FUS1 exhibits a low basal level of transcription that is increased 10-fold or more by treatment of the cell with pheromone. In addition, FUS1 transcription is undetectable in strains harboring null mutations in any of these five STE genes, implying that the basal transcription results from endogenous activity of the pathway in the absence of pheromone stimulation (McCaffrey et al. 1987; Hagen et al. 1991). We exploited these properties of the FUS1 promoter to select suppressors of a deletion in the STE4 gene (ste $4 \triangle:: L E U 2)$. A fragment that includes the FUS1 upstream activation sequence was joined to the HIS3 open reading frame to create a hybrid gene (FUS1::HIS3), which was integrated at the FUS1 locus by one-step gene replacement (see Materials and methods). Transcription of FUS1::HIS3 was inducible by pheromone and dependent on the STE genes (data not shown). Thus, his $3 \Delta S T E^{+}$cells containing FUS1::HIS3 grew without the addition of exogenous histidine, whereas his $3 \Delta$ ste $4 \Delta:: L E U 2$ cells containing FUS1::HIS3 did not (Table 1).

We used the his $3 \Delta$ ste $4 \Delta:: L E U 2$ FUS1::HIS3 strain (SY1436) and selected mutants that could grow in the absence of histidine (see Materials and methods). To identify suppressor mutations that led to activation of the pathway, rather than cis-acting mutations that affected only the expression of the FUS1::HIS3 construct, the initial collection of $\mathrm{His}^{+}$mutants was screened for suppression of two other ste $4 \Delta$ phenotypes. First, ste $4 \Delta$ mutants secrete much less pheromone than wild-type strains do because an intact pathway is required for efficient transcription of the pheromone structural genes (Fields and Herskowitz 1985; Fields et al. 1988). Second, ste $4 \Delta$ mutants cannot mate. Nine suppressors that secreted substantial amounts of $\alpha$-factor (Fig. 1) and had regained some degree of mating ability were isolated by selection and subsequent screening of $\sim 10^{8}$ cells.

To obtain a quantitative measure of the degree of suppression conferred by these mutations, three assays were performed. First, the level of expression of FUS1::HIS3 was assessed by determining the level of resistance that the mutants exhibited to aminotriazole (AT), a competitive inhibitor of the HIS3 enzyme (Klopotowski and Wiater 1965; Struhl and Davis 1977). All suppressors were at least as resistant to AT as the isogenic $S T E^{+}$ strain, and four were able to grow in the presence of 40 mM AT, the highest concentration tested (Table 1). A second measure of transcriptional activity, expression of a FUS1-lacZ reporter plasmid, revealed that all mutants expressed substantial levels of $\beta$-galactosidase, comparable to or greater than an isogenic $S T E^{+}$strain (Table 1). Four of the mutants expressed higher levels of $\beta$-galactosidase than the wild-type strain did after treatment with pheromone. Finally, by a quantitative assay, the suppressor mutants mated one to four orders of magni- 
Table 1. Transcription and mating phenotypes of the ste $4 \Delta$ suppressors

\begin{tabular}{|c|c|c|c|c|}
\hline Strain $^{a}$ & Dominance $^{b}$ & $\mathrm{AT}$ resistance $(\mathrm{mM})^{\mathrm{c}}$ & FUS1-1acZ expression ${ }^{\mathrm{d}}$ & Mating efficiency \\
\hline ste $4 \Delta$ & & $\mathrm{His}^{-}$ & 0.3 & $<5 \times 10^{-8}$ \\
\hline 1 & $\mathrm{D}$ & 40 & 240 & $9.3 \times 10^{-5}$ \\
\hline 4 & $\mathrm{D}$ & 40 & 204 & $2.7 \times 10^{-4}$ \\
\hline 12 & $\mathrm{D}$ & 10 & 6.9 & $3.1 \times 10^{-6}$ \\
\hline 13 & $\mathrm{D}$ & 10 & 22.3 & $5.3 \times 10^{-6}$ \\
\hline 14 & $\mathrm{D}$ & 1 & 6.3 & $8.6 \times 10^{-6}$ \\
\hline 25 & $\mathrm{R}$ & 2.5 & 58.3 & $1.3 \times 10^{-6}$ \\
\hline 26 & $\mathrm{D}$ & 40 & 247 & $5.1 \times 10^{-4}$ \\
\hline 27 & $\mathrm{R}$ & 10 & 147 & $4.0 \times 10^{-5}$ \\
\hline 29 & $\mathrm{D}$ & 40 & 11.3 & $6.7 \times 10^{-5}$ \\
\hline$S T E^{+}$ & & 1 & 13.9 & 0.81 \\
\hline$S T E^{+}+\mathbf{a}$-factor & & $N D^{f}$ & 104 & $\mathrm{ND}^{\mathrm{f}}$ \\
\hline
\end{tabular}

${ }^{a}$ All strains are isogenic to SY1390 $\left(M A T \alpha S T E^{+}\right.$FUS1::HIS3) except as indicated. Strains containing suppressor mutations were derived from SY1436 or SY1491 (MAT $\alpha$ ste 4A::LEU2 FUS1::HIS3).

bSuppressor mutations were determined to be dominant (D) or recessive (R) with respect to wild type, as described in Materials and methods.

cHighest concentration of AT tested that allowed growth on SD-His plates.

${ }^{d} \beta$-Galactosidase activity was determined as described in Materials and methods. The values reported are the average of assays of at least three independent transformants.

${ }^{\mathrm{e}}$ Absolute mating efficiencies are presented, determined as described in Materials and methods.

${ }^{\mathrm{f}}(\mathrm{ND})$ Not determined.

tude better than the parental ste4 $4:: L E U 2$ strain (Table 1).

To test whether the suppressor mutations were dominant or recessive, $M A T \alpha / M A T \alpha$ diploids that were heterozygous for the suppressor mutation were created by protoplast fusion. Seven of the suppressor mutations conferred growth in the absence of histidine and were therefore dominant. Two suppressors (25 and 27) were $\mathrm{His}^{-}$and therefore recessive.

\section{Suppressors include dominant alleles of STE11}

The mutants were isolated as suppressors of the transcription and mating defects caused by a deletion in the STE4 gene. To discover whether the suppressors required the activity of other response pathway genes, the STE5, STE7, STE11, or STE12 gene was deleted in each suppressor mutant and the resultant strain was tested for its ability to grow without exogenous histidine. By this criterion, all nine mutants could suppress a deletion in STE5 but not deletion of STE7, STE11, or STE12 (Table 2).

To test the possibility that the suppressor mutations were alterations of STE7, STE11, or STE12, we used gene disruption cassettes to knock out each of the candidate STE genes, reasoning that a dominant allele would be destroyed by a gene disruption. In particular, we used the ste 7 , ste 11 , and ste 12 deletion strains constructed above and assessed the His phenotype following introduction of a plasmid-borne version of the relevant wild-type STE

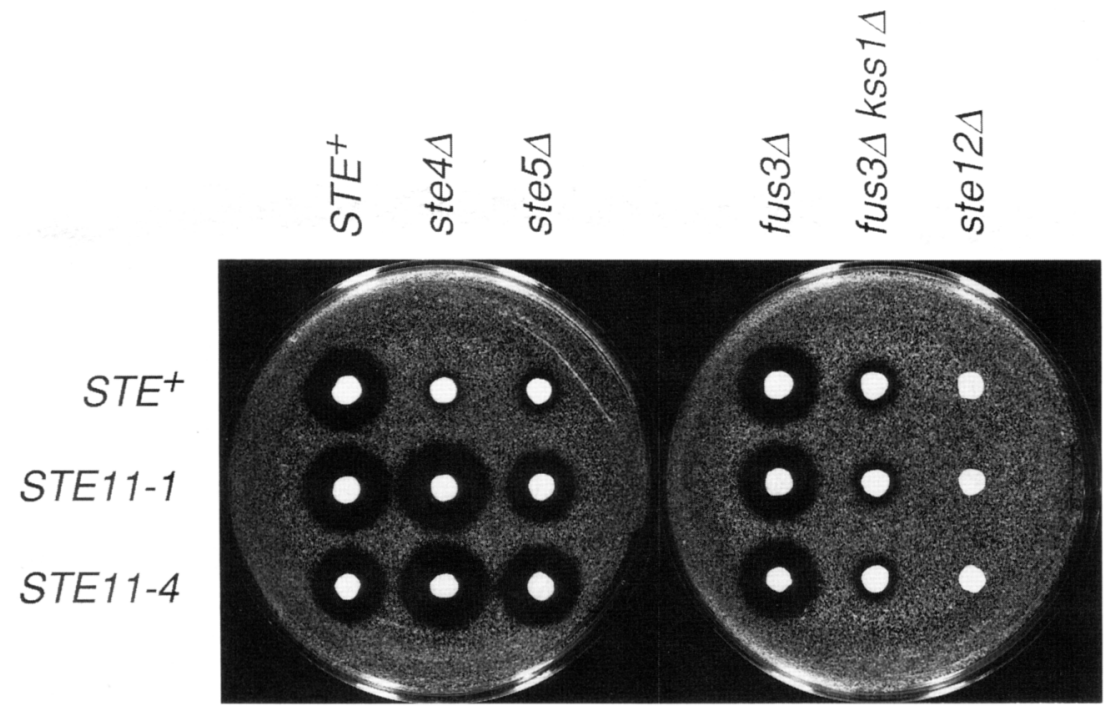

Figure 1. $\alpha$-factor production in suppressor strains. $S T E^{+}$and suppressor strains/designated STE11-1 and STE11-4, as explained later in the text) were spotted onto a lawn of supersensitive XMB4-12b (MATa sst1) cells. Where indicated, the strains carried ste4, ste5, fus 3 , fus 3 and kss 1 , or ste 12 mutations. The plates were incubated at room temperature for $24 \mathrm{hr}$. The diameter of the zone of growth inhibition (halo) surrounding the spotted strains reflects the amount of $\alpha$-factor secreted. 
Stevenson et al.

Table 2. Genetic requirements for suppressor activity

\begin{tabular}{|c|c|c|c|c|c|c|c|}
\hline \multirow{2}{*}{$\begin{array}{l}\text { Suppressor } \\
\text { strain }\end{array}$} & \multirow[b]{2}{*}{ ste $5 \Delta$} & \multicolumn{2}{|c|}{ ste $7 \Delta$} & \multicolumn{2}{|c|}{ ste $11 \Delta$} & \multicolumn{2}{|c|}{ 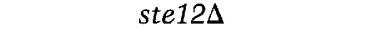 } \\
\hline & & - pSTE7 & $+\mathrm{p} S T E 7$ & - pSTE11 & $+\mathrm{p} S T E 11$ & - pSTE12 & $+\mathrm{p} S T E 12$ \\
\hline 1 & + & - & + & - & - & - & + \\
\hline 4 & + & - & + & - & - & - & + \\
\hline 12 & + & - & + & - & - & - & + \\
\hline 13 & + & - & + & - & - & - & + \\
\hline 14 & + & - & + & - & - & - & + \\
\hline 25 & + & - & + & - & + & - & + \\
\hline 26 & + & - & + & - & - & - & + \\
\hline 27 & + & - & + & - & + & - & + \\
\hline 29 & + & - & + & - & - & - & + \\
\hline
\end{tabular}

All strains are isogenic to SY1491 (MAT $\alpha$ ste4A::LEU2 FUS1::HIS3) except as indicated.

(+) $\mathrm{His}^{+}$phenotype; $\left(-1 \mathrm{His}^{-}\right.$phenotype.

gene (see Materials and methods). If the suppressor mutation was ablated by a ste gene disruption, then the plasmid-borne STE gene would not restore the $\mathrm{His}^{+}$phenotype to the ste $4 \Delta:: L E U 2$ suppressor strain. Conversely, if the suppressor mutation was not affected by the disruption, then the plasmid-borne STE gene would restore the original phenotype. By this criterion, the two recessive mutations (25 and 27) were not alleles of STE7, STE11, or STE12 (Table 2). On the other hand, all seven of the dominant mutations appeared to be STE11 alleles. This possibility was confirmed by rescuing the STE11 allele from each of the mutants by gap repair (Rothstein 1991; see Materials and methods). Upon introduction into a naive ste $4:: L E U 2$ strain, the repaired plasmids isolated from these seven mutants $(1,4,12,13,14,26$, and $29 \mid$ conferred the original suppressor phenotype: The cells were $\mathrm{His}^{+}$and produced high levels of pheromone.

Because the segment of DNA cloned by gap repair corresponded closely to the STE11 locus and because overexpression of wild-type STE11 does not lead to activation of FUS1::HIS3 (B. Stevenson and G. Sprague, unpubl.), we reasoned that the mutations were likely within the STE11-coding sequence. In fact, DNA sequence analysis of suppressor 1 revealed a $\mathrm{C} \rightarrow \mathrm{T}$ transition at nucleotide 950 [following the DNA sequence numbering of Rhodes et al. (1990)], which substitutes serine for proline at amino acid residue 279 (Fig. 2). This allele was designated STE11-1. The altered residue is within the large amino-terminal domain which, by analogy with other protein kinases, may have a regulatory function (Taylor et al. 1990). A transition mutation $(\mathrm{C} \rightarrow \mathrm{T})$ at nucleotide position 1902 was present in the six remaining mutants, leading to the replacement of threonine 596 by isoleucine. This allele was designated STE11-4. The altered residue is adjacent to the invariant Asp-Phe-Gly (DFG) triplet in subdomain VII according to the classification of Hanks et al. (1988) and lies at the heart of the proposed kinase catalytic site.

STE11-1 and STE11-4 exhibit similar, but distinct, phenotypes

The variability of phenotypes exhibited by the original isolates carrying the STE11-4 mutation, and the possibility that secondary mutations within the strains could alter the suppressor phenotype, prompted us to re-examine both STE11 alleles in defined isogenic backgrounds. In this isogenic setting, we investigated the effect of the STE11 alleles in strains that could respond to pheromone $\left(S T E 4^{+}\right)$or in strains that carried deletions in known components of the response pathway.

The wild-type STE11 gene in strain SY1390 (relevant genotype: MAT $\alpha S T E^{+}$FUS1::HIS3) was replaced by either the STE11-1 or the STE11-4 allele by two-step gene replacement (see Materials and methods). As expected, both alleles conferred a His ${ }^{+}$phenotype and high basal expression of FUS1-lacZ in an otherwise wild-type genetic background (Table 3 ) . However, by several criteria, the STE11-4 allele conferred a stronger phenotype than the STE11-1 allele. First, the expression of FUS1-lacZ was higher in STE11-4 strains than in STE11-1 strains. Second, although both alleles suppressed the mating defect caused by loss of the a-factor receptor $(s t e 3 \Delta)$ or of $\mathrm{G}_{\beta}$ (ste $4 \Delta$ ), strains carrying the STE11-4 allele exhibited a mating efficiency about two orders of magnitude greater than STE11-1 strains. Third, cells carrying the STE11-4 allele in an otherwise wild-type background grew noticeably slower than either isogenic STE11-1 or

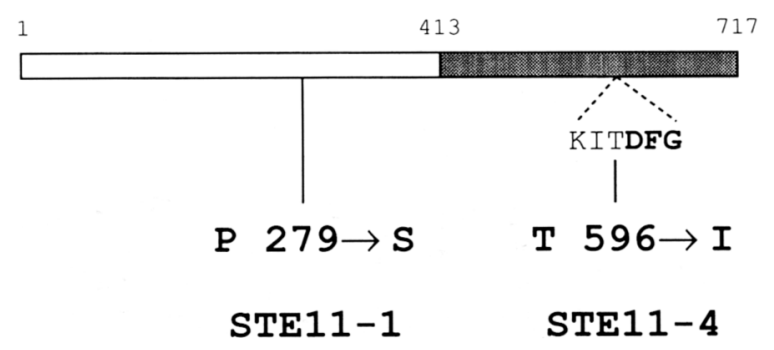

Figure 2. Location of the amino acid substitutions caused by the STE11-1 and STE11-4 mutations. The long rectangle represents the STE11 protein kinase; the region of protein kinase homology is shaded. Numbering of amino acids is from Rhodes et al. (1990). Conserved catalytic subdomain VII is shown, with invariant amino acid residues in boldface type (Hanks et al. 1988). 
Table 3. Transcription and mating activities of STE11-1 and STE11-4 in various genetic backgrounds

\begin{tabular}{|c|c|c|c|}
\hline Strain $^{a}$ & $\begin{array}{l}\mathrm{AT} \\
\text { resistance } \\
(\mathrm{mM})^{\mathrm{b}}\end{array}$ & $\begin{array}{l}\text { FUS1-lacZ } \\
\text { expression }^{c}\end{array}$ & $\begin{array}{l}\text { Mating } \\
\text { efficiency }^{\mathrm{d}}\end{array}$ \\
\hline STE11-1 & 40 & 233.8 & 0.90 \\
\hline STE11-1 ste $3 \Delta$ & 40 & 207.5 & $1.3 \times 10^{-5}$ \\
\hline STE11-1 ste4D & 40 & 160.4 & $2.9 \times 10^{-5}$ \\
\hline STE11-1 ste $5 \Delta$ & 1 & 4.8 & $<4 \times 10^{-8}$ \\
\hline STE11-1 ste $7 \Delta$ & $\mathrm{His}^{-}$ & 0.1 & $<7 \times 10^{-8}$ \\
\hline STE11-1 ste $12 \Delta$ & $\mathrm{His}^{-}$ & 0.1 & $<4 \times 10^{-8}$ \\
\hline STE11-1 fus3A & 40 & 147.7 & $1.7 \times 10^{-2}$ \\
\hline STE11-1 fus $3 \Delta$ kss1 & $\mathrm{His}^{-}$ & $\mathrm{ND}^{\mathrm{e}}$ & $<4 \times 10^{-8}$ \\
\hline STE11-4 & 40 & 341.9 & 0.93 \\
\hline STE11.4 ste $3 \Delta$ & 40 & 258.4 & $7.1 \times 10^{-4}$ \\
\hline STE11-4 ste $4 \Delta$ & 40 & 300.6 & $2.0 \times 10^{-3}$ \\
\hline STE11-4 ste $5 \Delta$ & 30 & 49.4 & $<4 \times 10^{-8}$ \\
\hline STE11-4 ste7A & $\mathrm{His}^{-}$ & 0.1 & $<9 \times 10^{-8}$ \\
\hline STE11-4 ste12A & $\mathrm{His}^{-}$ & 0.1 & $<6 \times 10^{-8}$ \\
\hline STE11-4 fus $3 \Delta$ & 40 & 321.5 & $2.2 \times 10^{-2}$ \\
\hline STE11-4 fus $3 \Delta \mathrm{kss} 1 \Delta$ & $\mathrm{His}^{-}$ & $\mathrm{ND}^{\mathrm{e}}$ & $<3 \times 10^{-8}$ \\
\hline$S T E^{+}$ & 1 & 17.4 & 0.81 \\
\hline ste $3 \Delta$ & 1 & 16.8 & $<4 \times 10^{-8}$ \\
\hline ste4s & His - & 0.3 & $<5 \times 10^{-8}$ \\
\hline ste $5 \Delta$ & $\mathrm{His}^{-}$ & 0.3 & $<2 \times 10^{-8}$ \\
\hline ste12A & $\mathrm{His}^{-}$ & 0.1 & $<5 \times 10^{-8}$ \\
\hline$S T E^{+}$fus $3 \Delta$ & 5 & 29.3 & $1.0 \times 10^{-2}$ \\
\hline$S T E^{+}$fus $3 \Delta$ kss $1 \Delta$ & $\mathrm{His}^{-}$ & $\mathrm{ND}^{\mathrm{e}}$ & $<3 \times 10^{-8}$ \\
\hline
\end{tabular}

${ }^{a}$ All strains are isogenic to SY1390 (MATa STE ${ }^{+}$FUS1::HIS3) except as indicated.

${ }^{\mathrm{b}}$ Highest concentration of AT tested that allowed growth on SD-His plates.

${ }^{\mathrm{c}} \beta$-Galactosidase activity was determined as described in Materials and methods. The values reported are the average of assays of at least three independent transformants.

${ }^{\mathrm{d}}$ Absolute mating efficiencies are presented, determined as described in Materials and methods.

e(ND) Not determined.

STE11 strains. Microscopic examination of exponențial phase STE11-4 cells revealed a significant proportion of large cells with projections or other aberrant morphologies, which were not present in the isogenic STE11 culture (Fig. 3). STE11-4 ste $4 \Delta$ strains also exhibited projection formation (Fig. 3), as did STE11-4 ste3A (data not shown), but STE11-4 ste12A strains exhibited wild-type morphology (Fig. 3). These findings are again consistent with the idea that the pathway is activated at a step downstream of $G_{\beta}$ but before STE12.

To complete the epistasis analysis in these isogenic strains, we constructed ste5, ste 7 , and ste 12 derivatives of the STE11-1 and STE11-4 mutants. Both alleles conferred a His ${ }^{+}$phenotype in ste $5 \Delta$ strains but not in ste $7 \Delta$ or ste12 $\Delta$ strains (Table 3), confirming the results obtained with the original suppressor mutants. However, quantitative mating analysis and transcription assays revealed that ste $5 \Delta$ was suppressed only partially (Table 3). Moreover, the growth and morphological defects of the STE11-4 allele were not seen in the ste $5 \Delta$ strain (data not shown). These results imply that the phenotype of the
STE11 mutant strains is a composite of the signal generated by the mutant kinases and of a STE5-dependent signal.

Recently, two additional genes required for the activity of the response pathway have been identified. These genes, FUS3 (Elion et al. 1990) and KSS1 (Courchesne et al. 1989), are partially redundant in function and appear to encode related protein kinases. Deletion of FUS3 alone has little effect on transcription induction but blocks cell cycle arrest in response to pheromone. Deletion of both genes blocks transcription induction and cell cycle arrest (Elion et al. 1991; G. Ammerer, A. Amon, and K. Nasmyth, pers. comm.). As shown in Table 3 , deletion of both genes abolished both the transcription and mating phenotypes of the STE11-1 and STE11-4 strains, suggesting that FUS3/KSS1 functions at a step after STE1 1 in the pathway. Although these genetic data do not exclude more complicated relationships, biochemical data from Gartner et al. (this issue) support this simple relationship (see Discussion).

\section{STE11 controls the phosphorylation state of the STE7 protein kinase}

The STE7 protein kinase is hyperphosphorylated in cells treated with pheromone (Z.-Q. Zhou and B. Errede, unpubl.). To determine whether STE11 activity affects the phosphorylation state of STE7, we examined the STE7 protein in strains expressing either the STE11-1 or STE11-4 allele. It is not possible to detect wild-type levels of STE7; hence, STE7 was overproduced to permit immunodetection. Because overproduction of STE7 does not influence pheromone response in otherwise wildtype cells, these experiments are likely to give an accurate representation of the post-translational changes in STE7 during response. Treatment of wild-type cells with pheromone increased the intensity of the slower migrating forms of STE7, which are characteristic of hyperphosphorylation (Fig. 4, lane 3; Z.-Q. Zhou and B. Errede, unpubl.). In the absence of pheromone, expression of the STE11-1 or STE11-4 allele led to an increase in the proportion of slower migrating forms of STE7 (Fig. 4, cf. lanes 7 and 8 with lane 4). This result suggested that STE11 affects the phosphorylation state of STE7 and reinforced the idea that STE11 acts before STE7 in the pathway.

The phenotypes conferred by the dominant STE11 alleles require a functional FUS3/KSS1 activity (Table 3). In concert with this physiological relationship between STE11 and FUS3/KSS1, the hyperphosphorylated forms of STE7 were depleted in STE11-1 (or STE11-4) fus3A kss $1 \Delta$ strains. The extent of STE7 hyperphosphorylation was indistiguishable from that seen in an untreated $S T E^{+}$fus $3 \Delta$ kss $1 \Delta$ strain (Fig. 4, cf. lanes 10 and 11 with lane 9). These findings indicate that FUS3/KSS1 activity is required for STE7 modification by the constitutive STE11 kinases.

\section{Discussion}

In the yeast pheromone response pathway, a signal is 

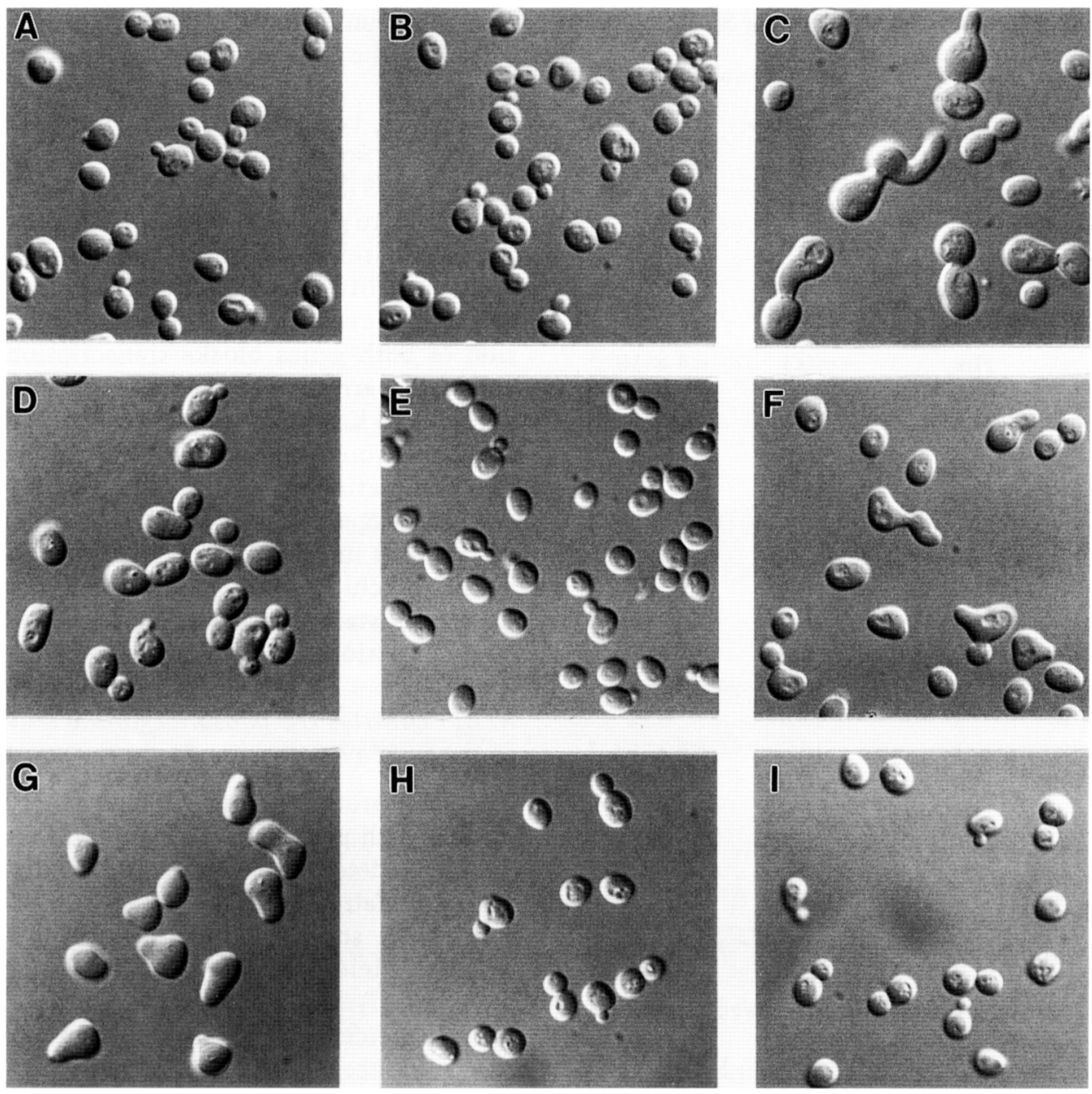

Figure 3. Cellular morphology of STE11-1 and STE11-4 strains. Isogenic strains were grown in rich medium to exponential phase. A, $S T E^{+} ; \mathrm{D}$, ste $4 \Delta ; \mathbf{G}, S T E^{+}$after treatment with a-factor; B, STE11-1; E, STE11-1 ste4A; H, STE11-1 ste12A; C, STE11-4; F, STE11-4 ste $4 \Delta ;$ I, STE11-4 ste12A. Cells were fixed and photographed as described in Materials and methods.

transmitted from the cell surface to the nucleus, where a change in transcription of select genes occurs, leading ultimately to the characteristic physiological response. The events that take place at the cell surface and in the nucleus have been well studied, but the nature and order of events that constitute the signal that connects these two locales are poorly understood. To gain insight into this central portion of the pathway, we identified mutants with a constitutively active pathway. A number of these mutants harbor dominant mutations in STE11, which encodes a protein kinase required for activity of the pathway. Below, we discuss the implications of these findings for the organization of the pathway and for the regulation of kinase activity.

\section{Organization of the pheromone response pathway}

The majority of components that participate in the pheromone response pathway have been identified by the isolation of mutants with a nonresponsive phenotype (MacKay and Manney 1974; Hartwell 1980). However, because the mutants exhibit an identical phenotype, the functional relationships among the gene products are largely unknown. Prior to this work, the relative positions of two components had been established by genetic analyses. First, the $\mathrm{G}$ protein acts at an early, but postreceptor, step in the pathway. This conclusion came from the analysis of strains in which perturbations in the activity or quantity of STE4 $\left(G_{\beta}\right)$ led to constitutive activation of the pathway (Blinder et al. 1989; Cole et al. 1990; Whiteway et al. 1990; Elion et al. 1991). The constitutive phenotype allowed strains lacking receptors to mate, but the phenotype was blocked by loss-of-function mutations in STE5, STE7, STE11, STE12, and FUS3/ KSS1. These results place the G protein after the receptors, but its relationship to the STE and FUS3/KSS1 products is uncertain. These products may function after the $\mathrm{G}$ protein, or they may be required for its activity. Second, a transcription factor, STE12, required for the transcription of genes whose products execute response, was placed at the end of the pathway. This placement follows from the finding that overexpression of STE12 
STE

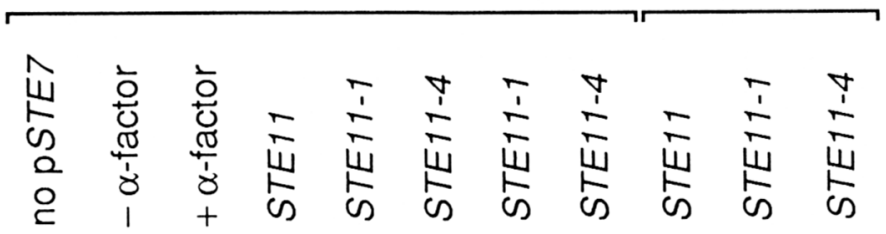

MCM1 -

$-1$

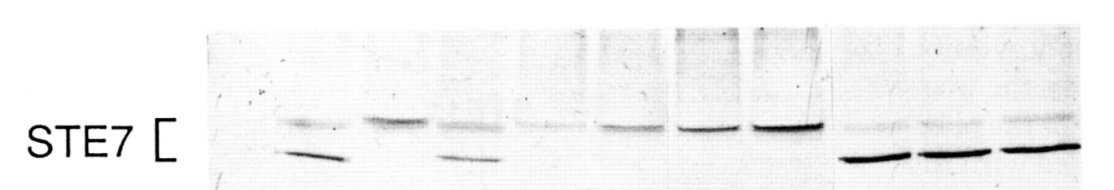

fus $3 \Delta k s s 1 \Delta$

Figure 4. Post-translational modification of the STE7 protein kinase. STE7 protein was detected in protein extracts by western analysis as described in Materials and methods. STE7 exists in two forms; the slower migrating species is hyperphosphorylated (Z.-Q. Zhou and B. Errede, unpubl.). The level of MCMl protein served as a control for the amount of protein extract loaded in each lane. (Lane 1) $\mathrm{STE}^{+}$no pNC279; (lane 2) MATa $S T E^{+}$; (lane 3) MATa $S T E^{+}$treated with $5 \mathrm{mM}$ $\alpha$-factor for $3 \mathrm{hr}$ (lane 4) $S T E^{+}$; (lanes 5,7 ) STE11-1; (lanes 6,8) STE11-4; (lane 9) $S T E^{+}$ fus3-6::LEU2 kss1A::URA3; (lane 10) STE11-1 fus3-6::LEU2 kss1A::URA3; (lane 11) STE11-4 fus3-6::LEU2 kss1A::URA3. All strains are MAT $\alpha$ and contained pNC279 (CYC1-STE7), unless otherwise stated. Overexpression of STE7 in STE11-1 and STE11-4 strains that are otherwise wild type for the signal transduction pathway leads to a growth defect. Because plasmid loss provides a means to overcome the detrimental effect of STE7, only $\sim 30 \%$ of the cells in cultures of these strains contain the STE7 plasmid, compared with $\sim 80 \%$ of the cells in cultures of the other strains (data not shown). Consequently, there is less STE7 protein in the extracts loaded in lanes 5 and 6 than in other lanes. To facilitate comparison with other lanes, three times more protein from these extracts was loaded in lanes 7 and 8 .

led to a constitutive phenotype even in strains lacking the STE and FUS3/KSS1 products (Dolan and Fields 1990; Elion et al. 1991).

The isolation of STE11 alleles that confer a constitutive phenotype has allowed us to infer the relationships among additional pathway components. First, we conclude that STE11 functions after STE4. The dominant STE11 alleles suppress all defects associated with loss of STE4 activity. Second, we conclude that STE11 functions after at least some STE5 activities because the dominant STE11 mutations suppress the lack of transcription of FUS1 and other genes seen in ste $5 \Delta$ strains. However, the STE11 alleles do not suppress the mating defect of ste $5 \Delta$ strains. Two models can be proposed to explain the quantitative difference in suppression of ste $4 \Delta$ and ste $5 \Delta$. The simpler model supposes that STE4, STE5, and STE11 exhibit a linear relationship and supposes further that STE5 is required for optimal activity of the STE11 kinase. The second model supposes that the pheromone response pathway branches at the STE4 or STE5 step, creating two independent signals, one of which operates through STE11. Together, these signals influence the activity of STE12 and perhaps other proteins involved in mating.

Finally, we conclude that STE 11 acts before STE7 and FUS3/KSS1. The genetic data establish that STE7 and FUS3/KSS1 are required for the STE11 mutant phenotype but do not establish their relationship in the pathway. However, biochemical analysis of wild-type and mutant strains reveals that STE11 influences the phosphorylation state and presumably the activity of STE7 and FUS3/KSS1. When wild-type cells are treated with pheromone, STE7 protein is phosphorylated rapidly in a STE11-dependent manner. The increased phosphoryla- tion of STE7 apparently increases its kinase activity (Z.Q. Zhou and B. Errede, unpubl.), although the possibility that the phosphorylation represents an adaptive response to pheromone has not yet been excluded. Hyperphosphorylation of STE7 is also observed in the STE11-1 and STE11-4 constitutive mutants, even in the absence of added pheromone. In a parallel effort, Gartner et al. (this issue) have shown that FUS3 rapidly becomes phosphorylated after pheromone treatment. As is thought to be the case for STE7, the phosphorylated form of FUS3 appears to be the active kinase. Phosphorylation of FUS3 requires STE11 function and occurs in STE11-1 and STE11-4 strains even in the absence of pheromone. These data therefore place STE7 and FUS3 after STE11 in the pheromone response pathway.

What is the relationship between STE7 and FUS3? In this case, evidence suggests an interdependent rather than linear relationship. Phosphorylation of STE7, either on pheromone stimulation or in the STE11 mutant strains, requires FUS3/KSS1 (this work; Zhou and Errede 1992), and likewise, phosphorylation of FUS3 under either condition requires STE7 (Gartner et al., this issue). Thus, we suggest that STE7 and FUS3/KSS1 require each other to become active. Perhaps they carry out mutual phosphorylation or form a complex. This model rationalizes the properties of a presumptive gain-of-function mutation in FUS3. The phenotype conferred by this allele is abolished by deletion of STE7 or STE11 (J. Brill, E. Elion, and G. Fink, pers. comm.), not because STE7 and STE11 function after FUS3 but because STE11 and STE7 must operate to generate phosphorylated FUS3, which appears to be the active form of the protein.

The genetic requirements for phosphorylation of STE7 and FUS3 are the same whether mediated by pheromone 
or by STE11 mutation, implying that the two conditions are equivalent mechanistically. Thus, we suggest that in the normal course of pheromone response the activity of STE11 increases, which leads to increased phosphorylation of STE7 and FUS3 and an attendant increase in the activity of those kinases. Whether STE11 acts directly on STE7 and FUS3 or acts through an intermediary protein or proteins is not known. Targets of STE7 and FUS3 may include STE12, which is believed to exhibit increased ability to activate transcription on phosphorylation (Song et al. 1991). Our results therefore imply the presence of a protein kinase cascade at the center of the pheromone response pathway. This insight, coupled with the results of others (Dietzel and Kurjan 1987; Miyajima et al. 1987; Nakayama et al. 1988; Blinder et al. 1989; Dolan and Fields 1990), suggests that most of the pathway components function in a linear sequence. Thus far, the only exception is the relationship between STE7 and FUS3. As discussed above, there may be a branchpoint at the STE5 step, but in the absence of direct evidence for this possibility, we will assume the simpler, linear relationship (Fig. 5).

\section{Regulation of the kinase activity of STE11}

Protein kinases typically consist of a catalytic domain and a regulatory domain, which is either part of the same polypeptide or is present on a second subunit (Taylor et al. 1990). The protein kinase encoded by STE11 is a large protein comprised of 717 residues. The kinase catalytic domain occupies the carboxy-terminal half of the protein (Fig. 3; Rhodes et al. 1990). The function of the large amino-terminal portion of the protein is unknown, but by analogy with other protein kinases this domain may have a role in regulating the activity of the catalytic domain. The position and nature of the amino acid substitutions in the constitutive STE 11 mutants suggest how the activity of STE 11 may be regulated.

The STE11-1 mutant protein has serine substituted for proline in the middle of the amino-terminal putative regulatory domain. Although in principle this domain could have either a positive or negative regulatory role, we favor the latter possibility for several reasons. In this view, the negative regulatory function has been inactivated by the amino acid substitution, which leads to increased activity of the catalytic domain as revealed by phosphorylation of STE7. Consistent with this proposed negative role is the finding that overproduction of the amino-terminal domain of STE 11 makes cells resistant to $\alpha$-factorinduced cell-cycle arrest (N. Rhodes and B. Errede, unpubl.). A similar result has been obtained for byr2, a putative protein kinase from Schizosaccharomyces pombe (Wang et al. 1991), which is $42 \%$ identical to STE11 (B. Stevenson, unpubl.) and is required for mating and sporulation by that organism. Overexpression of the byr2 amino terminus reduces sporulation, indicative of a reduction in signal strength in that pathway (Wang et al. 1991). Finally, the amino-terminal segments of other serine/threonine kinases, for example, Raf-1 (Stanton 1989 |, are known to have negative regulatory roles.
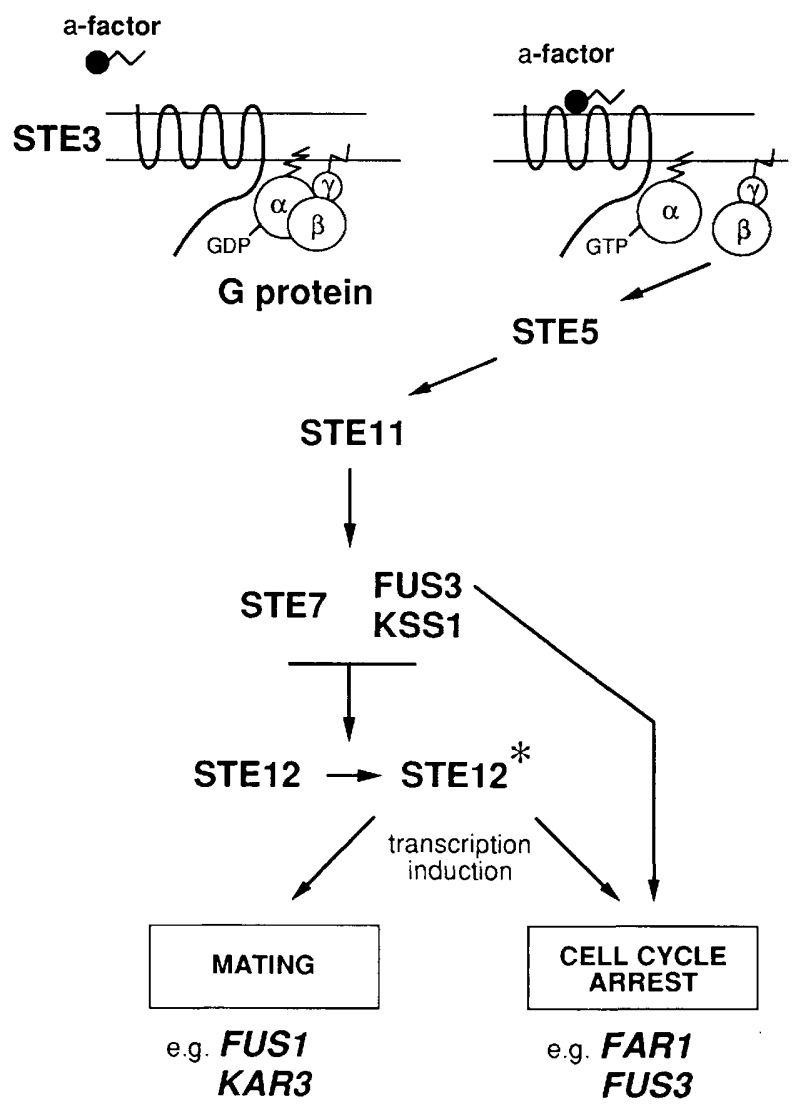

Figure 5. A model for the pheromone response pathway. This schematic incorporates results from this work and elsewhere. In $\alpha$ cells, the binding of a-factor to the receptor encoded by STE3 (or $\alpha$-factor binding to STE2 in a cells) results in the exchange of GTP for GDP on the $\alpha$-subunit of the G protein [encoded by GPA1 (SCG1), and its dissociation from the $\beta$ and $\gamma$ subunits (encoded by STE4 and STE18). $\mathrm{G}_{\beta \gamma}$ transmits the signal through STE5 and the protein kinases, causing a change in the modification state of the transcription factor STE12. STE12* represents the phosphorylated form that appears to have transcriptional activity. As discussed in the text, STE7 and FUS3/KSS1 may have an interdependent relationship. Examples of inducible genes involved in mating and cell cycle arrest are given. FUS1 is required for cell fusion and KAR3 for nuclear fusion. FAR 1 and FUS 3 cause cell cycle arrest by affecting $\mathrm{G}_{1}$ cyclin accumulation. Pheromone-mediated post-translational modification of FARl and FUS3, in addition to their increased abundance as a result of increased transcription, is likely essential to achieve cell cycle arrest.

The STE11-4 mutant protein has isoleucine substituted for threonine in the catalytic domain, adjacent to the invariant Asp-Phe-Gly triplet, which is thought to be involved in ATP binding at the catalytic site (Hanks et al. 1988; Knighton et al. 1991). An intriguing possibility is that the threonine residue is a site of negative regulation by phosphorylation, which would interfere with ATP binding. Substitution by isoleucine would remove this regulatory site, resulting in a constitutively active kinase. It is noteworthy that the analogous position in byr2 is a serine residue (Wang et al. 1991). Another pos- 
sibility is that the substitution enables STE 11 to interact more efficiently with its substrate. In this view, the properties of the mutant kinase do not result from loss of a negative regulatory mechanism but from a gain in intrinsic activity.

\section{Implications for signal transduction in other organisms}

Recent evidence indicates that the pheromone response pathway as deduced for the budding yeast $S$. cerevisiae is highly conserved in the fission yeast $S$. pombe. Pheromone receptors homologous to those of budding yeast have been identified for fission yeast (Kitamura and Shimoda 1991; M. Yamamoto, pers. comm.), and those receptors are coupled to G proteins (Obara et al. 1991). Equally noteworthy, two putative protein kinases, byrl and byr2, which are homologous to STE7 and STE11, are essential components of the pathway (Nadin-Davis and Nasim 1988; Wang et al. 1991; A. Neiman and I. Herskowitz, pers. comm.; B. Stevenson, unpubl.). Moreover, genetic analysis reveals that byr 2 and byrl function in the same order as do their budding yeast counterparts. Recently, DNA sequences that can encode a protein with homology to STE7 have been isolated from Drosophila melanogaster (A. Neiman, pers. comm.). As yet, no close relatives to STE11, other than byr2, have been identified in other species. However, given that $S$. cerevisiae and $S$. pombe have very similar signal transduction pathways despite the great evolutionary distance that separates them, it will be interesting to learn whether STE11 and STE7 homologs are key components in signal transduction processes in multicellular organisms.

\section{Materials and methods}

Strains, media, and microbiological techniques

The majority of yeast strains used in this work are isogenic

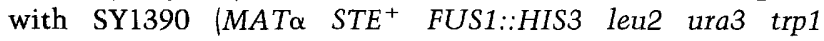

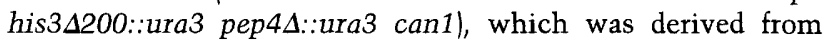
246-1-1 (MAT $\alpha$ leu2 ura3 trp1 his4-519 can1, provided by K. Tatchell) by one-step gene replacement at the relevant loci (Rothstein 1991). This strain contains the FUS1::HIS3 gene fusion at the FUS1 locus and is phenotypically Fus1- ${ }^{-}$. A ste $4 \triangle:: L E U 2$ version of this strain (SY1491) and its lys2 derivative (SY1436) were used for mutant isolation. In the genetic analysis of the mutants, ste deletion derivatives were produced by one-step gene replacement using ste5 $\Delta:: U R A 3$, ste $7 \Delta:: U R A 3$, ste11 $\triangle:: U R A 3$, and ste12A::URA3 DNA constructs. Strains containing the STE11-1 (SY1865) or STE11-4 (SY1866) alleles, in an otherwise wild-type background, were produced by integration of pSL1654 and pSL1655, respectively, at the STE11 locus in strain SY1390. Resolution of the tandem STE11 duplication was selected by resistance to 5-fluoro-orotic acid (Boeke et al. 1984), and Ura ${ }^{-}$colonies were screened phenotypically for the presence of the mutant allele. Deletion derivatives of SY1390 (STE ${ }^{+}$), SY1865 (STE11-1), and SY1866 (STE11-4) were produced by one-step gene replacement using ste $3 \Delta:: L E U 2$, ste $4 \Delta:: L E U 2$, ste $5 \Delta:: L E U 2$, ste12 $1:: L E U 2$, fus3$6:: L E U 2$, and kss $1 \Delta:: U R A 3$ DNA constructs. Three additional strains were used: DC5 (MATa leu2-3, -112 his3 gal2 can1; provided by J. Strathern); 227 (MATa lys1 cry1; provided by I. Herskowitz); XMB4-12b (MATa sst1-1 arg9 ilv3 ura1 his4; provided by L. Blair).

Yeast and bacterial strains were propagated using standard methods. YEPD and SD media have been described (Rose et al. 1990). Yeast transformations were performed as described by Beggs (1978) or by electroporation (Becker and Guarente 1991), except that sonicated, denatured salmon sperm DNA was included as carrier. Bacterial transformations, bacterial DNA preparations, and plasmid constructions were performed by standard methods (Sambrook et al. 1989).

\section{Plasmids}

FUS1::HIS3 (pSL1497) contains the HIS3 open reading frame driven by the FUS1 promoter, flanked by sequences to direct integration of the gene fusion to the FUS1 locus. Appropriate sites in FUS1 and HIS3 for the fusion point were created by Bal 31 digestion and SalI linker addition. The exact end points of the deletions used for the gene fusion were determined by DNA sequencing: for the FUS1 promoter, 3 bp upstream of the ATG; for the HIS 3 open reading frame, 22 bp upstream of the ATG. The FUS1::HIS3 fusion was created by ligating the FUS1 and HIS3 fragments in the pSPT18 vector (Pharmacia); subsequently, a 1.2-kb HincII fragment containing downstream FUS1 sequences was ligated into the SmaI site of the polylinker. Digestion with EcoRI releases a FUS1::HIS3 fragment that can recombine with and replace the native FUS1 locus. The FUS1lacZ plasmid used to assay FUS1 expression has been described (pSL307; McCaffrey et al. 1987).

A collection of plasmids was used to introduce deletions at the chromosomal STE loci: ste $4 \Delta:: L E U 2$ (p121; Whiteway et al. 1989); ste5A::URA3 (pSUREl, provided by J. Thorner); ste5 $\Delta:: L E U 2$ (pSL1180; this work); ste7 $\triangle:: U R A 3$ (pSL1077; this work); ste7 $\triangle 3:: L E U 2$ (pNC113; Company and Errede 1988); ste11A::URA3 (pSL1094; this work); ste12A::URA3 (pSL1311; this work); ste12A::LEU2 (pSUL-16; Fields and Herskowitz 1987); fus3-6::LEU2 (pYEE98; Elion et al. 1990); and $k s s 1 \Delta:: U R A 3$ (pGA1850, provided by G. Ammerer).

CEN-ARS plasmids with a selectable TRP1 marker were used to introduce STE genes into ste deletion strains: pSL1363, STE11 on a 5.6-kb SalI-BamHI fragment in pRS314 (Sikorski and Hieter 1989); pSL1364, STE12 on a 5.4-kb ClaI fragment in pRS314; $\mathrm{pSTE}^{+}{ }^{+}$, STE7 on a 5 -kb SacI fragment in pNC160 (Rhodes et al. 1990). pSL1506, used to clone the STE11 alleles, was constructed by replacing the BamHI-Sall fragment of YCp50 (Rose et al. 1987) with a 5.3-kb BamHI-Sall fragment from pSTE1 1.1 (Chaleff and Tatchell 1985) and deleting the 3.6$\mathrm{kb} X b a \mathrm{I}$ fragment that contains the entire STE11 gene. pSL1654 and pSL1655 contain the STE11-1 and STE11-4 alleles, repectively, as $3.6-\mathrm{kb} \mathrm{XbaI}$ fragments in a modified pRS306 vector (Sikorski and Hieter 1989) lacking the KpnI site in the polylinker. pNC279, a TRP1 CEN-ARS plasmid containing STE7 driven by the CYC1 promoter (provided by Z. Zhou), was used to facilitate detection of STE7 in Western analysis.

\section{Isolation and analysis of ste4s suppressor mutants}

Mutations that restore expression of FUS1::HIS3 to a ste $4 \Delta::$ LEU2 strain arise spontaneously at a frequency of $\sim 10^{-5}$ of cells plated on SD-His. In one experiment, aliquots of eight different cultures of strain SY1436 (relevant genotype MAT $\alpha$ ste $4 \Delta::$ LEU2 FUS1::HIS3 ura3 lys2) containing pSL307, a URA3 2- $\mu \mathrm{m}$ FUS1-lacZ reporter plasmid, were plated on SDHis-Ura. Only 1 colony of the 96 tested restored mating ability to the ste $4 \Delta$ strain. This isolate (mutant 1) also produced more 
$\alpha$-factor than the isogenic $S T E^{+}$parent (SY1390). To isolate more mutants with these phenotypes a culture of SY1491 (MAT $\alpha$ ste $4 \Delta:: L E U 2$ FUS1::HIS3) was mutagenized with ethylmethanesulfonate (70\% survival; Moir et al. 1982), and cells that expressed FUS1::HIS 3 were selected on SD-His plates. The frequency of colony formation was $1.5 \times 10^{-4}$. Eight mutants $(4,12,13,14,25,26,27$, and 29$)$ were selected for further study on the basis of secondary screens for pheromone production and mating competence.

The dominant or recessive nature of the suppressor mutations was determined by testing the expression of FUS1::HIS3 in $M A T \alpha / M A T \alpha$ diploids, formed by protoplast fusion (Schnell et al. 1989) of the ste $4 \Delta$ suppressor mutants with the parental ste $4 \Delta$ strain. A His ${ }^{-}$phenotype indicated that the mutation was recessive, whereas a $\mathrm{His}^{+}$phenotype indicated that the mutation was dominant. MAT $\alpha / M A T \alpha$ diploids heterozygous for the mutation in suppressor mutant 1 grew poorly on SD-His and produced a level of $\alpha$-factor intermediate between the original mutant and the parental ste $4 \Delta$ strain, suggesting that the mutation was incompletely dominant (codominant).

The ability of each ste $4 \Delta$ suppressor mutant to suppress deletions in other STE genes was determined by replacing the chromosomal copy of the relevant STE gene with a deletion allele marked by a URA3 gene (Rothstein 1991). Following confirmation of the genotype by Southern analysis, the His and pheromone production phenotypes of the deletion mutants were evaluated. In cases where the mutation did not suppress a particular ste deletion, the possibility that the suppressor mutation was allelic to the STE gene was determined by introducing a plasmid-borne copy of the STE gene. Failure to express FUS1::HIS 3 or to produce more $\alpha$-factor in the presence of the STE gene suggested that the suppressor was allelic to that gene. This result was confirmed by cloning the suppressor allele and testing its effect on the expression of FUS1::HIS3 in a naive ste $4 \triangle:: L E U 2$ strain.

\section{Cloning and sequencing of the STE11 alleles}

The STE11 alleles were cloned by the gap repair method (Rothstein 1991). Strains suspected of carrying a mutant STE11 allele were transformed to uracil prototrophy with pSL1506 linearized at the unique $\mathrm{XbaI}$ site. The $3.6-\mathrm{kb} \mathrm{XbaI}$ fragment rescued from each suppressor mutant was subcloned into M13mpl 8 for sequencing (Sanger et al. 1977), using synthetic primers complementary to the STE11 sequence. The DNA sequence of the entire STE11-coding region was determined for the STE11 alleles rescued from mutants 1 and 4, and from the wild-type isogenic strain (SY1491). A single nucleotide difference was detected between wild type and each of the mutants. Only the sequence spanning the change in STE11-4 was determined for alleles rescued from mutants $12,14,26$, and 29 . These alleles contain the same mutation present in STE11-4.

\section{$\beta$-Galactosidase, mating, and halo assays}

For $\beta$-galactosidase assays, strains carrying pSL307 were grown to mid-log phase at $30^{\circ} \mathrm{C}$ in selective medium. Cells were prepared and assayed as described previously (Jarvis et al. 1988). Quantitative mating assays were performed by a filter mating assay as described (Clark and Sprague 1989). Qualitative mating and pheromone production assays (halo assays) were performed according to Sprague (1991).

Preparation of yeast protein extracts and detection of STE7

STE11-1, STE11-4, and STE ${ }^{+}$strains harboring pNC279 were grown to saturation in SD-Trp and used to innoculate $250 \mathrm{ml}$ of
$\mathrm{S}$ broth-Trp medium containing $1 \%$ sucrose as the carbon source (to induce CYC1-STE7 expression). Cultures were harvested at a density of $\sim 2 \times 10^{7}$ cells $/ \mathrm{ml}$, and protein extracts were prepared as described (Company et al. 1988). Aliquots of protein $(25 \mu \mathrm{g} /$ lane, from $40 \%$ ammonium sulfate fractions) were fractionated on an $8 \%$ SDS-polyacrylamide gel (Laemmli 1970) and transferred to nitrocellulose. Rabbit anti-STE7 polyclonal antibodies were used to detect STE7 protein. Mouse antiMCM1 polyclonal antibodies (a gift of G. Ammerer) were used to detect MCM1 protein. The Promega Protoblot system with goat anti-rabbit or goat anti-mouse IgG conjugated to alkaline phosphatase was used to detect the primary antibody by colorimetric methods.

\section{Microscopy}

Cells were fixed in $3.7 \%$ formaldehyde $/ 0.15 \mathrm{M} \mathrm{NaCl}$ and sonicated briefly before mounting. Micrographs were taken on a Zeiss Axioplan photomicroscope with Nomarski optics, using a $100 \times$ objective.

\section{Acknowledgments}

We thank G. Ammerer, E. Elion, S. Fields, M. Johnston, V. MacKay, and J. Thorner for providing plasmids, and members of the laboratory for discussions and comments on the manuscript. We also thank G. Ammerer for communicating results before publication, and Z.-Q. Zhou for help with the Western analysis of STE7. This work was supported by U.S. Public Health Service research grants (GM30027 awarded to G.F.S. and GM39852 awarded to B.E.) and by Faculty Research Award FRA282 from the American Cancer Society (to G.F.S.). B.J.S. was supported by a postdoctoral fellowship from the Swiss National Science Foundation and by a Damon Runyon-Walter Winchell Cancer Fund Fellowship (DRG-977).

The publication costs of this article were defrayed in part by payment of page charges. This article must therefore be hereby marked "advertisement" in accordance with 18 USC section 1734 solely to indicate this fact.

\section{References}

Becker, D.M. and L. Guarente. 1991. High-efficiency transformation of yeast by electroporation. Methods Enzymol. 194: 182-187.

Beggs, J.D. 1978. Transformation of yeast by a replicating hybrid plasmid. Nature 275: 104-109.

Bender, A.D. and G.F. Sprague Jr. 1986. Yeast peptide pheromones, a-factor and $\alpha$-factor, activate a common response mechanism in their target cells. Cell 47: 929-937.

Blinder, D., S. Bouvier, and D.D. Jenness. 1989. Constitutive mutants in the yeast pheromone response: Ordered function of the gene products. Cell 56: 479-486.

Blumer, K.J. and J. Thorner. 1990. $\beta$ and $\gamma$ subunits of a yeast guanine nucleotide-binding protein are not essential for membrane association of the $\alpha$ subunit but are required for receptor coupling. Proc. Natl. Acad. Sci. 87: 4363-4367.

Boeke, J.D., F. LaCroute, and G.R. Fink. 1984. A positive selection for mutants lacking orotidine-5'-phosphate decarboxylase activity in yeast: 5-Fluoro-orotic acid resistance. Mol. Gen. Genet. 197: 345-346.

Burkholder, A.C. and L.H. Hartwell. 1985. The yeast $\alpha$-factor receptor: Structural properties deduced from the sequence of the STE2 gene. Nucleic Acids Res. 13: 8463-8475.

Chaleff, D.T. and K. Tatchell. 1985. Molecular cloning and char- 
acterization of the STE7 and STE11 genes of Saccharomyces cerevisiae. Mol. Cell. Biol. 5: 1878-1886.

Chang, F. and I. Herskowitz. 1990. Identification of a gene necessary for cell cycle arrest by a negative growth factor of yeast: FAR1 is an inhibitor of a G1 cyclin, CLN2. Cell 63: 999-1011.

Clark, K.L. and G.F. Sprague Jr. 1989. Yeast pheromone response pathway: Characterization of a suppressor that restores mating to receptorless mutants. Mol. Cell. Biol. 9: 2682-2694.

Cole, G.M., D.E. Stone, and S.I. Reed. 1990. Stoichiometry of G protein subunits affects the Saccharomyces cerevisiae mating pheromone signal transduction pathway. Mol. Cell. Biol. 10: $510-517$.

Company, M. and B. Errede. 1988. A Tyl cell-type-specific regulatory sequence is a recognition element for a constitutive binding factor. Mol. Cell. Biol. 8: 5299-5309.

Company, M., C. Adler, and B. Errede. 1988. Identification of a Tyl regulatory sequence responsive to STE7 and STE12. Mol. Cell. Biol. 8: 2545-2554.

Courchesne, W.E., R. Kunisawa, and J. Thorner. 1989. A putative protein kinase overcomes pheromone-induced arrest of cell cycling in S. cerevisiae. Cell 58: 1107-1119.

Cross, F., L.H. Hartwell, C. Jackson, and J.B. Konopka. 1988. Conjugation in Saccharomyces cerevisiae. Annu. Rev. Cell Biol. 4: 429-457.

Dietzel, C. and J. Kurjan. 1987. The yeast SCG1 gene: A G $_{\alpha}$-like protein implicated in the a- and $\alpha$-factor response pathway. Cell 50: 1001-1010.

Dolan, J.W. and S. Fields. 1990. Overproduction of the yeast STE12 protein leads to constitutive transcriptional induction. Genes \& Dev. 4: 492-502.

Dolan, J.W., C. Kirkman, and S. Fields. 1989. The yeast STE12 protein binds to the DNA sequence mediating pheromone induction. Proc. Natl. Acad. Sci. 86: 5703-5707.

Elion, E.E., P.L. Grisafi, and G.R. Fink. 1990. FUS3 encodes a $\mathrm{cdc} 2+/ \mathrm{CDC} 28$-related kinase required for the transition from mitosis into conjugation. Cell 60: 649-664.

Elion, E.E., J.A. Brill, and G.R. Fink. 1991. FUS3 represses CLN1 and CLN2 and in concert with KSS1 promotes signal transduction. Proc. Natl. Acad. Sci. 88: 9392-9396.

Errede, B. and G. Ammerer. 1989. STE12, a protein involved in cell-type-specific transcription and signal transduction in yeast, is part of protein-DNA complexes. Genes \& Dev. 3: 1349-1361.

Fields, S. and I. Herskowitz. 1985. The yeast STE12 product is required for expression of two sets of cell-type-specific genes. Cell 42: 923-930.

- 1987. Regulation by the yeast mating-type locus of STE12, a gene required for cell-type-specific expression. Mol. Cell. Biol. 7: 3818-3821.

Fields, S., D.T. Chaleff, and G.F. Sprague Jr. 1988. Yeast STE7, STE11, and STE12 genes are required for expression of celltype-specific genes. Mol. Cell. Biol. 8: 551-556.

Hagen, D.C., G. McCaffrey, and G.F. Sprague Jr. 1986. Evidence the yeast STE3 gene encodes a receptor for the peptide pheromone a factor: Gene sequence and implications for the structure of the presumed receptor. Proc. Natl. Acad. Sci. 83: 1418-1422.

Hagen, D.C., G. McCaffrey, and G.F. Sprague Jr. 1991. Pheromone response elements are necessary and sufficient for basal and pheromone-induced transcription of the FUS1 gene of Saccharomyces cerevisiae. Mol. Cell. Biol. 11: 29522961.

Hanks, S.K., A.M. Quinn, and T. Hunter. 1988. The protein kinase family: Conserved features and deduced phylogeny of the catalytic domains. Science 241: 42-52.
Hartwell, L. 1980. Mutants of Saccharomyces cerevisiae unresponsive to cell division control by polypeptide mating hormone. J. Cell Biol. 85: 811-822.

Jahng, K., J. Ferguson, and S.I. Reed. 1988. Mutations in a gene encoding the $\alpha$ subunit of a Saccharomyces cerevisiae G protein indicate a role in mating pheromone signaling. Mol. Cell. Biol. 8: 2484-2493.

Jarvis, E.E., D.C. Hagen, and G.F. Sprague Jr. 1988. Identification of a DNA segment that is necessary and sufficient for $\alpha$-specific gene control in Saccharomyces cerevisiae: Implications for regulation of $\alpha$-specific and a-specific genes. Mol. Cell. Biol. 8: 309-320.

Jenness, D.D., A.C. Burkholder, and L.H. Hartwell. 1983. Binding of $\alpha$-factor pheromone to yeast a cells: Chemical and genetic evidence for an $\alpha$-factor receptor. Cell 35: 521-529.

Kitamura, K. and C. Shimoda. 1991. The Schizosaccharomyces pombe mam 2 gene encodes a putative pheromone receptor which has a significant homology with the Saccharomyces cerevisiae Ste2 protein. EMBO I. 10: 3743-3751.

Klopotowski, T. and A. Wiater. 1965. Synergism of aminotriazole and phosphate on the inhibition of yeast imidazole glycerol phosphate dehydratase. Arch. Biochem. Biophys. 112: $562-566$.

Knighton, D.R., J. Zheng, L.F. TenEyck, V.A. Ashford, N. Xuong, S.A. Taylor, and J.M. Sowadski. 1991. Crystal structure of the catalytic subunit of cyclic adenosine monophosphate-dependent protein kinase. Science 253: 407-414.

Laemmli, U.K. 1970. Cleavage of structural proteins during the assembly of the head of bacteriophage T4. Nature 227: 680685.

MacKay, V. and T.R. Manney. 1974. Mutations affecting sexual conjugation and related processes in Saccharomyces cerevisiae. II. Genetic analysis of nonmating mutants. Genetics 76: 272-288.

Marsh, L., A.M. Neiman, and I. Herskowitz. 1991. Signal transduction during pheromone response in yeast. Annu. Rev. Cell Biol. 7: 699-728.

McCaffrey, G., F.J. Clay, K. Kelsay, and G.F. Sprague Jr. 1987. Identification and regulation of a gene required for cell fusion during mating of the yeast Saccharomyces cerevisiae. Mol. Cell. Biol. 7: 2680-2690.

Meluh, P.B. and M.D. Rose. 1990. KAR3, a kinesin-related gene required for yeast nuclear fusion. Cell 60: 1029-1041.

Miyajima, I., M. Nakafuku, N. Nakayama, C. Brenner, A. Miyajima, K. Kaibuchi, K. Arai, Y. Kaziro, and K. Matsumoto. 1987. GPA1, a haploid-specific essential gene, encodes a yeast homolog of mammalian $G$ protein which may be involved in the mating factor-mediated signal transduction pathway. Cell 50: 1011-1019.

Moir, D., S.E. Stewart, B.C. Osmond, and D. Botstein. 1982. Cold-sensitive cell-division-cycle mutants of yeast: Isolation, properties, and pseudoreversion studies. Genetics 100: $547-563$.

Nadin-Davis, S.A. and A. Nasim. 1988. A gene which encodes a predicted protein kinase can restore some functions of the ras gene in fission yeast. EMBO J. 7: 985-993.

Nakafuku, M., H. Itoh, S. Nakamura, and Y. Kaziro. 1987. Occurrence in Saccharomyces cerevisiae of a gene homologous to the cDNA coding for the $\alpha$ subunit of mammalian $G$ proteins. Proc. Nat1. Acad. Sci. 84: 2140-2144.

Nakayama, N., A. Miyajima, and K. Arai. 1985. Nucleotide sequence of STE2 and STE3, cell type-specific sterile genes from Saccharomyces cerevisiae. EMBO I. 4: 2643-2648.

1987. Common signal transduction system shared by STE2 and STE3 in haploid cells of Saccharomyces cerevisiae: Autocrine cell-cycle arrest from forced expression of STE2. 
EMBO J. 6: 249-254.

Nakayama, N., Y. Kaziro, K. Arai, and K. Matsumoto. 1988. Role of STE genes in the mating factor signaling pathway mediated by GPA1 in Saccharomyces cerevisiae. Mol. Cell. Biol. 8: 3777-3783.

Nomoto, S., N. Nakayama, K. Arai, and K. Matsumoto. 1990. Regulation of the yeast pheromone response pathway by $\mathrm{G}$ protein subunits. EMBO J. 9: 691-696.

Obara, T., M. Nakafuku, M. Yamamoto, and Y. Kaziro. 1991. Isolation and characterization of a gene encoding a G-protein $\alpha$ subunit from Schizosaccharomyces pombe: Involvement in mating and sporulation pathways. Proc. Natl. Acad. Sci. 88: $5877-5881$.

Rhodes, N., L. Connell, and B. Errede. 1990. STE11 is a protein kinase required for cell-type-specific transcription and signal transduction in yeast. Genes \& Dev. 4: 1862-1874.

Rose, M.D., P. Novick, J.H. Thomas, D. Botstein, and G.R. Fink. 1987. The Saccharomyces cerevisiae genomic plasmid bank based on a centromere-containing shuttle vector. Gene 60: $237-243$.

Rose, M.D., F. Winston, and P. Hieter. 1990. Methods in yeast genetics. Cold Spring Harbor Laboratory Press, Cold Spring Harbor, New York.

Rothstein, R. 1991. Targeting, disruption, replacement, and allele rescue: Integrative DNA transformation in yeast. Methods Enzymol. 194: 281-301.

Sambrook, J., E.F. Fritsch, and T. Maniatis. 1989. Molecular cloning: A laboratory manual, 2nd ed. Cold Spring Harbor Laboratory Press, Cold Spring Harbor, New York.

Sanger, F., S. Nicklen, and A.R. Coulson. 1977. DNA sequencing with chain-terminating inhibitors. Proc. Natl. Acad. Sci. 74: 5463-5467.

Schnell, R., L. D'Ari, M. Foss, D. Goodman, and J. Rine. 1989. Genetic and molecular characterization of suppressors of SIR4 mutations in Saccharomyces cerevisiae. Genetics 122: $29-46$.

Sikorski, R.S. and P. Hieter. 1989. A system of shuttle vectors and yeast host strains designed for efficient manipulation of DNA in Saccharomyces cerevisiae. Genetics 122: 19-27.

Song, O., J.W. Dolan, Y.O. Yuan, and S. Fields. 1991. Pheromone-dependent phosphorylation of the yeast STE12 protein correlates with transcriptional activation. Genes \& Dev. 5: 741-750.

Sprague, G.F. Ir. 1991. Assay of yeast mating reaction. Methods Enzymol. 194: 77-93.

Stanton, V.P. Jr., D.W. Nichols, A.P. Laudano, and G.M. Cooper. '1989. Definition of the human raf amino-terminal regulatory region by deletion mutagenesis. Mol. Cell. Biol. 9: 639647.

Struhl, K. and R.W. Davis. 1977. Production of a functional eukaryotic enzyme in Escherichia coli: Cloning and expression of the yeast structural gene for imidazoleglycerolphosphate dehydratase (his3). Proc. Natl. Acad. Sci. 74: 52555259.

Taylor, S.S., J.A. Buechler, and W. Yonemoto. 1990. cAMP-dependent protein kinase: Framework for a diverse family of regulatory enzymes. Annu. Rev. Biochem. 59: 971-1005.

Teague, M.A., D.T. Chaleff, and B. Errede. 1986. Nucleotide sequence of the yeast regulatory gene STE7 predicts a protein homologous to protein kinases. Proc. Natl. Acad. Sci. 83: $7371-7375$.

Trueheart, J., J.D. Boeke, and G.R. Fink. 1987. Two genes required for cell fusion during yeast conjugation: Evidence for a pheromone-induced surface protein. Mol. Cell. Biol. 7: 2316-2328.

Wang, Y., H. Xu, M. Riggs, L. Rodgers, and M. Wigler. 1991. byr2, a Schizosaccharomyces pombe gene encoding a protein kinase capable of partial suppression of the ras1 mutant phenotype. Mol. Cell. Biol. 11: 3554-3563.

Whiteway, M., L. Hougan, D. Dignard, D.Y. Thomas, L. Bell, G.C. Saari, F.J. Grant, P. O'Hara, and V.L. MacKay. 1989. The STE4 and STE18 genes of yeast encode potential $\beta$ and $\gamma$ subunits of the mating factor receptor-coupled $G$ protein. Cell 56: 467-477.

Whiteway, M., L. Hougan, and D.Y. Thomas. 1990. Overexpression of the STE4 gene leads to mating response in haploid Saccharomyces cerevisiae. Mol. Cell. Biol. 10: 217-222. 


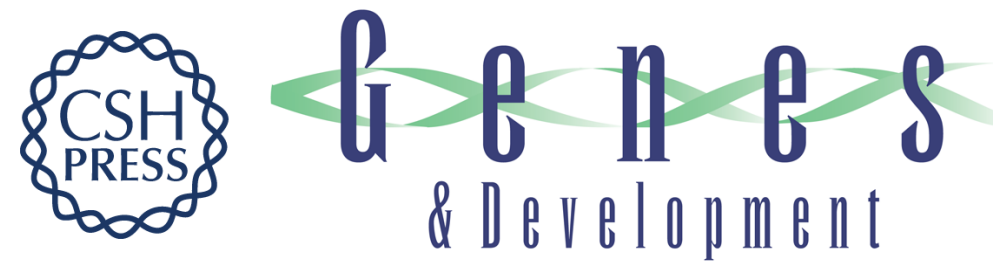

\section{Constitutive mutants of the protein kinase STE11 activate the yeast pheromone response pathway in the absence of the G protein.}

B J Stevenson, N Rhodes, B Errede, et al.

Genes Dev. 1992, 6:

Access the most recent version at doi:10.1101/gad.6.7.1293

References This article cites 64 articles, 35 of which can be accessed free at:

http://genesdev.cshlp.org/content/6/7/1293.full.html\#ref-list-1

License

Email Alerting

Service

Receive free email alerts when new articles cite this article - sign up in the box at the top right corner of the article or click here.

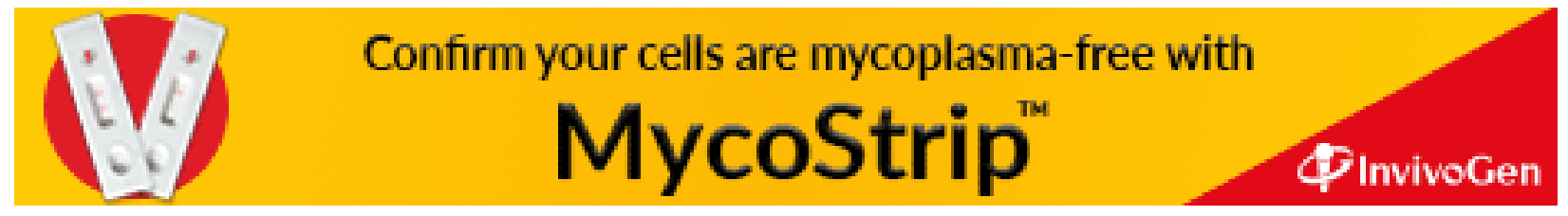

